\title{
EVALUASI PEMAKAIAN ANTIBIOTIK DI INSTALASI GAWAT DARURAT RUMAH SAKIT BAPTIS KEDIRI PERIODE APRIL - JUNI 2021
}

\author{
Evaluation of Antibiotic use in The Emergency Installation of Baptis Hospital Kediri \\ Period April - June 2021
}

\author{
Yenny Ardiyanti ${ }^{1}$ Tsamrotul Ilmi $^{2}$ Arlita Wulan Yuniar ${ }^{3}$ \\ $1,2,3$ \\ Program Studi S-1 Farmasi Fakultas Ilmu Kesehatan Universitas Kadiri \\ Alamat Korespondensi : : Jl. Selomangleng No.1, Pojok, Kec. Mojoroto, \\ Kota Kediri, Jawa Timur - Indonesia 64115 \\ E-mail : yeniardianti2207.ya@gmail.com
}

\begin{abstract}
ABSTRAK
Rumah Sakit adalah institusi pelayanan kesehatan yang menyelenggarakan pelayanan kesehatan perorangan secara paripurna serta menyediakan pelayanan rawat inap, rawat jalan, dan gawat darurat. Pelayanan kegawatdaruratan sebagai pelayanan di rumah sakit yang berfungsi dalam tindakan medis yang dibutuhkan oleh pasien. Antibiotika sebagai salah satu pengobatan utama dalam penatalaksanaan pengobatan penyakit. Tujuan penelitian ini untuk mengetahui gambaran pemakaian antibiotik dan evaluasi pemakaian antibiotik di Instalasi Gawat Darurat RS Baptis Kediri. Jenis penelitian yang digunakan adalah penelitian observasional dengan pendekatan deskriptif. Pengambilan data secara prospektif dari pengamatan saat pasien masuk IGD dan diamati selama pasien dirawat. Data didapatkan pada awal penelitian, kemudian dilakukan pengamatan mengikuti kejadian selama diberikan antibiotik. Hasil penelitian menunjukkan antibiotik yang sering digunakan adalah golongan Cefalosporin $(67,1 \%)$ dan Quinolon $(25,9 \%)$, sedangkan untuk jenis antibiotik yang sering digunakan adalah Ceftriaxone $(31,0 \%)$ dan Levofloxacin $(24,1 \%)$. Kesesuaian antibiotik dibandingkan dengan Pedoman Penggunaan Antibiotik sudah sesuai $100 \%$. Manfaat yang diharapkan dari penelitian ini, dapat memberikan masukan dan menjadi referensi untuk evaluasi Pedoman Penggunaan Antibiotik dan kepatuhan pasien dalam menggunakan antibiotik.
\end{abstract}

Kata Kunci : antibiotik, IGD, rumah sakit

\section{ABSTRACT}

Hospital is a health service institution that provides complete individual health services and provides inpatient, outpatient, and emergency services. Emergency services are services in hospitals that function in medical actions needed by patients. Antibiotics as one of the main treatments in the management of disease treatment. The purpose of this study was to describe the use of antibiotics and to evaluate the use of antibiotics in the Emergency Installation of Baptist Hospital Kediri. The type of research used is observational research with a descriptive approach. Prospective data collection from observations when the patient entered the $E R$ and observed during the patient's stay. The data was obtained at the beginning of the study, then observations were made following the incident while being given antibiotics. The results showed that the most commonly used antibiotics were cephalosporins (67.1\%) and quinolones (25.9\%), while the most frequently used antibiotics were Ceftriaxone (31.0\%) and Levofloxacin (24.1\%). The suitability of antibiotics compared to the Guidelines for Antibiotic Use was 100\% appropriate. The expected benefits of this study, can provide input and become a reference for the evaluation of the Antibiotic Use Guidelines and patient compliance in using antibiotics.

Keywords: antibiotics, emergency room, hospital 


\section{PENDAHULUAN}

Rumah Sakit adalah institusi pelayanan kesehatan yang menyelenggarakan pelayanan kesehatan perorangan secara paripurna yang menyediakan pelayanan rawat inap, rawat jalan, dan gawat darurat. (Undang Undang No 44 tahun 2009; PMK 30 tahun 2019). Rumah sakit mempunyai tugas untuk melaksanakan upaya kesehatan yang berdaya guna dan berhasil guna dengan mengutamakan penyembuhan dan pemulihan yang dilaksanakan secara serasi dan terpadu dalam peningkatan dan pencegahan serta pelaksanaan upaya rujukan dalam memberikan pelayanan kesehatan peroranagan secara paripurna (UU No 4 tahun 2009; Rikomah, 2017).

Pelayanan Kegawatdaruratan menjadi salah satu pelayanan di rumah sakit mempunyai fungsi dalam tindakan medis yang dibutuhkan oleh pasien pada kondisi gawat darurat dalam waktu segera untuk menyelamatkan nyawa dan pencegahan kecacatan. Fasilitas Pelayanan Kesehatan yang menyelenggarakan Pelayanan Kegawatdaruratan harus memiliki sumber daya manusia serta sarana, prasarana, obat dan bahan medis habis pakai. IGD adalah salah satu unit pelayanan di Rumah Sakit yang menyediakan penanganan awal bagi pasien yang datang langsung atau bagi pasien rujukan dari fasilitas pelayanan kesehatan lain ataupun dari pusat pelayanan keselamatan terpadu/ Public Safety Center (PSC) 119 (Permenkes 47, 2018).
Pelayanan farmasi di IGD dipimpin oleh seorang apoteker.Pelayanan farmasi yang dilakukan di IGD berupa sistem resep individual (resep perseorangan). Tugas dan fungsi dari pelayanan farmasi di IGD meliputi pelayanan perbekalan farmasi untuk pasien yang masuk ke IGD, baik pada jam kerja maupun diluar jam kerja dan hari libur, Melayani pasien umum serta pasien gawat darurat, pelayanan perbekalan farmasi untuk pasien yang memerlukan tindakan bedah yang dilakukan 24 jam di Instalasi Gawat Darurat.(Asrida,2016).

Pemberian antibiotika merupakan salah satu pengobatan utama dalam penatalaksanaan penyakit terutama penyakit infeksi.Penggunaan antibiotik secara bijak memerlukan kebijakan pembatasan dalam penerapannya. Antibiotik dibedakan dalam kelompok antibiotik yang bebas digunakan oleh semua klinisi (non-restricted) dan antibiotik yang dihemat dan penggunaannya memerlukan persetujuan tim ahli (restricted dan reserved). Keberhasilan penggunaan obat dapat diketahui dengan indikator peresepan yang digunakan untuk menilai penggunaan obat di fasilitas pelayanan kesehatan, sehingga diperoleh gambaran tentang pola dan kebiasaan peresepan serta situasi penggunaan obat, karena pada tempat pelayanan kesehatan penggunaan obat selalu dimulai dengan peresepan untuk mencapai pengobatan yang efektif, aman dan ekonomis (Permenkes No 8, 2015). 
Studi menemukan sekitar $\quad 40-62 \%$ antibiotik digunakan secara tidak tepat antara lain untuk penyakit-penyakit yang sebenarnya tidak memerlukan antibiotik. Pada penelitian kualitas penggunaan antibiotik di berbagai bagian rumah sakit ditemukan 30\% sampai dengan 80\% tidak didasarkan pada indikasi (Hadi, 2009, Permenkes 2406 tahun 2011). Tingkat penggunaan antibiotika relatif tinggi. Di negara maju, $13-37 \%$ dari seluruh pasien yang dirawat di Rumah Sakit mendapatkan antibiotika secara tunggal maupun kombinasi. Di Indonesia, 30- $80 \%$ pasien yang dirawat di Rumah Sakit mendapatkan antibiotika (Hanifah, 2018). Hasil penelitian dari Studi Antimicrobial Resistence in Indonesia (AMRIN study) tahun 2000 - 2004 menunjukan bahwa terapi antibiotik diberikan tanpa indikasi di RSUP Dr Kariadi Semarang sebanyak $20-53 \%$ dan antibiotik profilaksis tanpa indikasi sebanyak 43 81\%. (KS Negara, 2014). Menurut penelitian Heningtyas pada tahun 2017, persentase penggunaan antibiotik di ruang rawat inap Rumah Sakit "X" Provinsi Jawa Barat masih tergolong tinggi dengan persentase terendahnya pun sudah mencapai 44,3\%, sedangkan target penggunaan antibiotik oleh rumah sakit tersebut adalah $<30 \%$ persentase pasien rawat inap tertinggi yang menggunakan antibiotik pada Periode November-Desember 2017 adalah pasien obstetri dan ginekologi, yaitu masing-masing sebesar 74,7\% dan 76,3\%. (Heningtyas, 2018)
Rumah Sakit Baptis Kediri adalah salah satu rumah sakit di Kota Kediri yang berdiri pada bulan Februari 1954. Sebagai Rumah Sakit yang terakreditasi paripurna memiliki 200 tempat tidur dengan melayani pasien umum, pasien asuransi, pasien Inhealth dan pasien BPJS. Rumah Sakit Baptis memiliki Instalasi Gawat Darurat yang melayani pasien datang 24 jam. Jumlah pasien IGD pada tahun 2020 sebanyak 17.485 pasien dengan rata rata yang pasien perbulan 1457 pasien.

Evaluasi penggunaan antibiotik merupakan salah satu indikator mutu program pengendalian resistensi antibiotik di Rumah Sakit Baptis yang bertujuan memberikan informasi pola penggunaan antibiotik di Rumah Sakit baik kuantitas maupun kualitas. Pelaksanaan evaluasi penggunaan antibiotik di Rumah Sakit menggunakan sumber data dan metode secara standar yang dilakukan di Rumah Sakit Baptis. IGD Rumah Sakit Baptis menjadi bagian yang penting sebagai unit pelayanan yang menjadi tujuan pasien dalam keadaan darurat dari Kediri dan sekitarnya. Berdasarkan latar belakang diatas maka peneliti tertarik untuk meneliti tentang evaluasi pemakaian antibiotik di Instalasi Gawat Darurat Rumah Sakit Baptis Kediri periode bulan April - Juni 2021. 
Penelitian ini merupakan penelitian observasional dengan pendekatan deskriptif. Peneliti melakukan observasi, tanpa memberikan intervensi pada variable yang diteliti. Metode pengambilan sampel dengan menggunakan metode prospektif, yaitu melalui resep data rekam medis elektronik pasien instalasi gawat darurat RS Baptis Kediri pada Periode April - Juni 2021.

\section{HASIL DAN PEMBAHASAN}

Data penelitian didapatkan hasil menurut klasifikasi jenis kelamin sebagai berikut

Tabel 1. Distribusi Frekuensi Responden Berdasarkan Jenis Kelamin

\begin{tabular}{lcr}
\hline $\begin{array}{l}\text { Jenis } \\
\text { Kelamin }\end{array}$ & Frekuensi & Persentase\% \\
\hline Laki Laki & 302 & $52 \%$ \\
\hline Perempuan & 280 & $48 \%$ \\
\hline TOTAL & $\mathbf{5 8 2}$ & $\mathbf{1 0 0 \%}$ \\
\hline
\end{tabular}

Sumber Data : Data Primer 2021

Tabel 1. menunjukkan bahwa jumlah pasien jenis kelamin laki-laki adalah 302 pasien ( 52\%) lebih banyak dari pasien dengan jenis kelamin perempuan 280 pasien (48\%), Hal ini dilihat dari faktor jumlah populasi menurut sensus penduduk Indonesia tahun 2019, menurut menyebutkan bahwa dalam 101 penduduk laki laki, terdapat 100 perempuan maka menjadi logis jika kondisi keadaaan pasien lebih banyak dari laki laki (Badan Pusat Statistik,2020).
Tabel 2 Distribusi penggunaan Antibiotik berdasarkan usia pasien

\begin{tabular}{|c|c|c|}
\hline $\begin{array}{l}\text { Kualifikasi } \\
\text { Usia }\end{array}$ & Frekuensi & Persentase\% \\
\hline $\begin{array}{lr}\text { Masa } & \text { balita } \\
\text { usia } 0 & -5 \\
\text { tahun } & \end{array}$ & 49 & $8 \%$ \\
\hline $\begin{array}{l}\text { Masa kanak- } \\
\text { kanak usia } 5- \\
11 \text { tahun }\end{array}$ & 15 & $3 \%$ \\
\hline $\begin{array}{l}\text { Masa remaja } \\
\text { awal usia } 12- \\
16 \text { tahun }\end{array}$ & 11 & $2 \%$ \\
\hline $\begin{array}{l}\text { Masa remaja } \\
\text { akhir usia } 17- \\
25 \text { tahun }\end{array}$ & 46 & $8 \%$ \\
\hline $\begin{array}{l}\text { Masa dewasa } \\
\text { awal usia } 26- \\
35 \text { tahun }\end{array}$ & 66 & $11 \%$ \\
\hline $\begin{array}{l}\text { Masa dewasa } \\
\text { akhir usia } 36- \\
45 \text { tahun }\end{array}$ & 58 & $10 \%$ \\
\hline $\begin{array}{l}\text { Masa lansia } \\
\text { awal usia } 46- \\
55 \text { tahun }\end{array}$ & 89 & $15 \%$ \\
\hline $\begin{array}{l}\text { Masa lansia } \\
\text { akhir usia } 56- \\
65 \text { tahun }\end{array}$ & 149 & $26 \%$ \\
\hline $\begin{array}{l}\text { Masa manula } \\
\text { usia } 65-\text { ke } \\
\text { atas }\end{array}$ & 99 & $17 \%$ \\
\hline TOTAL & 582 & $100 \%$ \\
\hline
\end{tabular}

Berdasarkan tabel 2 dapat 3 golongan usia tertinggi yang mendapat resep antibiotic adalah pasien Lansia akhir ( usia 56 - 65 tahun) sebanyak 149 (26\%), diikuti pasien manula sebanyak 99 orang (17\%), dan lansia awal sebanyak 89 orang (15\%). Hal ini karena pada kategori lanjut usia mengalami penurunan fungsi organ, hal ini disebabkan oleh adanya faktor alamiah maupun penyakit, (Wahyuningsih R, 2019). Umur 60 tahun manusia menjadi lebih pendek, jantung tidak bereaksi secepat dulu, peredaran darah berlahan-lahan mulai terganggu, dan 
pencernaan tidak begitu baik lagi. Masalah psikologis yang paling umum yang berpengaruh pada lansia adalah timbulnya depresi, dimensia, dan mengigau (Windri, 2019). Banyaknya aktifitas yang dilakukan dapat dengan mudah terserang penyakit infeksi. Kesehatan lansia menunjukkan
$51,08 \%$ mengalami keluhan kesehatan dengan angka kesakitan 26,20\%. Hal ini akan mempengaruhi kondisi kesehatan lansia dalam menjalani aktifitas dan kehidupan masa tuanya (Ezalina (2021).

\section{Tabel 3 Distribusi Penggunaan Antibiotik Berdasarkan Golongan}

\begin{tabular}{|c|c|c|c|c|c|c|}
\hline No & Golongan Antibiotik & $\mathrm{Jml}$ & Persentase & Jenis Antibiotik & Jumlah & Persentase \\
\hline 1 & \multirow[t]{6}{*}{ Cefalosporin } & \multirow[t]{6}{*}{499} & \multirow[t]{6}{*}{$67,1 \%$} & Ceftriaxone (injeksi) & 231 & $31,0 \%$ \\
\hline & & & & Cefotaxime (injeksi) & 53 & $7,1 \%$ \\
\hline & & & & Cefixime (tablet) & 42 & $5,6 \%$ \\
\hline & & & & Cefadroxil (Tablet) & 13 & $1,7 \%$ \\
\hline & & & & $\begin{array}{l}\text { Cefoperazone+Sulbactam } \\
\text { (Injeksi) }\end{array}$ & 148 & $19,9 \%$ \\
\hline & & & & Cefuroxime (Injeksi) & 12 & $1,6 \%$ \\
\hline \multirow[t]{2}{*}{2} & \multirow[t]{2}{*}{ Quinolon } & \multirow[t]{2}{*}{193} & \multirow[t]{2}{*}{$25,9 \%$} & Ciprofloxacin (Injeksi) & 14 & $1,9 \%$ \\
\hline & & & & Levofloxacin (Injeksi) & 179 & $24,1 \%$ \\
\hline 3 & Betalaktam & 11 & $1,5 \%$ & Meropenem (injeksi) & 11 & $1,5 \%$ \\
\hline \multirow[t]{3}{*}{4} & \multirow[t]{3}{*}{ Makrolida } & \multirow[t]{3}{*}{13} & \multirow[t]{3}{*}{$1,7 \%$} & Azithromicin (Tablet) & 4 & $0,5 \%$ \\
\hline & & & & Erytromicin (Tablet) & 5 & $0,7 \%$ \\
\hline & & & & Clindamycin (Tablet) & 4 & $0,5 \%$ \\
\hline \multirow[t]{2}{*}{5} & \multirow[t]{2}{*}{ Penisilin } & \multirow[t]{2}{*}{18} & \multirow[t]{2}{*}{$2,4 \%$} & Amoxicillin (Injeksi) & 17 & $2,3 \%$ \\
\hline & & & & $\overline{\text { Co-Amoxiclave (Tablet) }}$ & 1 & $0,1 \%$ \\
\hline 6 & Tetrasiklin & 4 & $0,5 \%$ & Doxycyclin (Tablet) & 4 & $0,5 \%$ \\
\hline 7 & Kloramfenikol & 4 & $0,5 \%$ & Thiamfenikol (Sirup) & 4 & $0,5 \%$ \\
\hline \multirow[t]{2}{*}{8} & Cotrimoxazole & 2 & $0,3 \%$ & Cotrimoxazole (tablet) & 2 & $0,3 \%$ \\
\hline & Jumlah & 744 & $100 \%$ & & 744 & $100,00 \%$ \\
\hline
\end{tabular}

Tiga golongan antibiotik terbanyak yang diresepkan pada pasien IGD RS Baptis Kediri antara bulan April - Juni 2021 adalah golongan Cefalosporin (67,1\%), Quinolon $(25,9 \%)$ dan Penisilin (2,4\%). Jenis antibiotika terbanyak digunakan adalah Ceftriaxone $(31,0 \%)$, Levofloxacin $(24,1 \%$ dan Cefoperazone+Sulbactam $(19,9 \%)$.
Berdasarkan jenis penyakitnya, penyakit yang terbanyak adalah Coronavirus infection, Pneumonia dan Bronchopneumonia. Pilihan Antibiotika untuk Terapi Pneumonia komunitas berdasarkan ATS/IDSA 2019 adalah terapi kombinasi golongan Cefalosporin (Setiadi, 2020).

Pada pedoman tata laksana Covid-19, 
Coronavirus infection dengan gejala pneumonia menggunakan antibiotik Levofloxacin dalam pengobatannya. Dengan melihat jenis penyakit dan jenis antibiotik maka sesuai antara jenis penyakit dengan jenis antibiotiknya sebagai jenis yang paling banyak ditemukan (Burhan,2020).

Tabel 4 Sepuluh besar jenis penyakit di IGD

\begin{tabular}{clc}
\hline No & Jenis Penyakit & Jumlah \\
\hline 1. & Coronavirus infection, & 91 \\
\hline 2. & Pneumonia, unspecified & 35 \\
\hline 3. & Bronchopneumonia, unspecified & 34 \\
\hline 4. & Chronic kidney disease, stage 5 & 17 \\
\hline 5. & Dengue fever [classical dengue] & 17 \\
\hline 6. & Febrile convulsions & 17 \\
\hline 7. & Fever, unspecified & 13 \\
\hline 8. & Typhoid fever & 13 \\
\hline 9. & Unstable angina & 13 \\
\hline 10. & Acute appendicitis & 10 \\
\hline
\end{tabular}

\section{Kesesuaian Terapi}

Kesesuaian terapi mempunyai tujuan dalam memberikan perlindungan kepada pasien serta masyarakat dari cara penggunaan obat yang tidak rasional dalam rangka memenuhi kebutuhan dan keselamatan pasien. Pada penelitian ini dilakukan pengamatan kesesuaian terapi berdasarkan pedoman terapi panduan praktik klinis yang memuat empat hal yaitu tepat indikasi, tepat jenis obat, tepat dosis serta tepat cara dan lama pemberian. Data penelitian ada $21 \%$ yang tidak sesuai dan $79 \%$ yang seusai. Ketidak sesuaian di temukan pada pasien dengan 2 penyakit Coronavirus infection, unspecified, dan Pneumonia, unspecified . Kedua penyakit ini memiliki gejala yang mirip. Gejala pasien COVID-19 memiliki spektrum yang luas, mulai dari tanpa gejala (asimtomatk), gejala ringan, pneumonia, pneumonia berat, ARDS, sepsis,hingga syok sepsis (Susilo,2020). Penyakit Coronavirus infection belum tercantum dalam Panduan Penggunaan Antibiotik Rumah Sakit Baptis Kediri, sehingga tidak ada pembandingatau pedoman. Sedangkan untuk 2 penyakit lain, dari hasil konsultasi dengan dokter pemberi resep tetap diberikan antibiotik karena kondisi yang memburuk pada foto dada. Kondisi ini membuat antibiotik dilanjutkan.

\section{Tabel 5 Lima Penyakit, Antibiotik dan Kesesuaian} dengan Pedoman PenggunaanAntibiotik

\begin{tabular}{lllll}
\hline \multirow{2}{*}{ No Penyakit } & \multicolumn{1}{c}{ Antibiotik } & Sediaan & $\begin{array}{c}\text { Kesesuaian } \\
\text { umur dan } \\
\text { dosis }\end{array}$ & $\begin{array}{c}\text { Kesesuian } \\
\text { waktu dan } \\
\text { frekuensi }\end{array}$ \\
\hline $\begin{array}{l}\text { 1. } \\
\text { Coronavirus } \\
\text { infection, unspecified }\end{array}$ & Levofloxacin & Injeksi & Sesuai & Seusai \\
\cline { 2 - 5 } & Azithromicin & Tablet & Sesuai & Seusai \\
\cline { 2 - 5 } & Cefoperazone+Sulbactam & Injeksi & Sesuai & Seusai \\
\cline { 2 - 5 } & Ceftriaxon & Injeksi & Sesuai & Seusai \\
\hline
\end{tabular}




\begin{tabular}{|c|c|c|c|c|c|}
\hline & & Levofloxacin & Injeksi & Sesuai & Seusai \\
\hline \multirow[t]{7}{*}{2.} & \multirow{7}{*}{$\begin{array}{l}\text { Pneumonia, } \\
\text { unspecified }\end{array}$} & Cefoperazone+Sulbactam & Injeksi & Sesuai & Seusai \\
\hline & & Cefotaxim & Injeksi & Sesuai & Seusai \\
\hline & & Cefratam & Injeksi & Sesuai & Seusai \\
\hline & & Ceftriaxon & Injeksi & Sesuai & Seusai \\
\hline & & Ciprofloxacin & Injeksi & Sesuai & Seusai \\
\hline & & Levofloxacin & Injeksi & Sesuai & Seusai \\
\hline & & Cefixime & Sirup & Sesuai & Seusai \\
\hline \multirow[t]{4}{*}{3 . } & \multirow{4}{*}{$\begin{array}{l}\text { Bronchopneumonia, } \\
\text { unspecified }\end{array}$} & Cefoperazone+Sulbactam & Injeksi & Sesuai & Seusai \\
\hline & & Cefotaxim & Tablet & Sesuai & Seusai \\
\hline & & Ceftriaxon & Injeksi & Sesuai & Seusai \\
\hline & & $\overline{\text { Levofloxacin }}$ & Injeksi & Sesuai & Seusai \\
\hline \multirow[t]{3}{*}{4} & \multirow{3}{*}{$\begin{array}{l}\text { Chronic kidney } \\
\text { disease }\end{array}$} & Amoxicillin & Tablet & Sesuai & Seusai \\
\hline & & Cefoperazone+Sulbactam & Injeksi & Sesuai & Seusai \\
\hline & & Ceftriaxon & Injeksi & Sesuai & Seusai \\
\hline \multirow[t]{2}{*}{5} & \multirow{2}{*}{$\begin{array}{l}\text { Dengue fever } \\
\text { [classical dengue] }\end{array}$} & Ceftriaxon & Injeksi & Sesuai & Seusai \\
\hline & & Cefotaxim & Injeksi & Sesuai & Seusai \\
\hline
\end{tabular}

\section{Tepat Dosis}

Tepat dosis adalah ketepatan jumlah obat yang diberikan pada pasien dimana dosis berada dalam range dosis terapi yang direkomendasikan serta disesuaikan dengan usia pasien, berat badan pasien, luas permukaan tubuh pasien, kondisi pasien misalnya anak dengan berat lebih dari 60 kilo biasanya disarankan menggunakan dosis dewasa usia lanjut atau pasien dengan kerusakan ginjal dan hati biasanya memerlukan penyesuaian dosis. Pemberian dosis yang berlebihan atau overdosis akan sangat beresiko menimbulkan efek samping bahkan membahayakan jiwa terutama obat yang dengan rentang terapi sempit, sebaliknya dosis yang terlalu kecil atau underdose tidak akan menjamin tercapainya terapi yang diharapkan (BBKPM Bandung, 2019). Tepat dosis pada pasien di IGD RS Baptis telah memenuhi ketentuan dengan Pedoman Penggunaan Antibiotik 100\%.

\section{Tabel 6 Ketepatan dosis pada pasienIGD}

\begin{tabular}{lcc}
\hline $\begin{array}{l}\text { Ketepatan } \\
\text { dosis }\end{array}$ & Jumlah & Persentase\% \\
\hline Tepat dosis & 744 & $100 \%$ \\
\hline $\begin{array}{l}\text { Tidak Tepat } \\
\text { Dosis }\end{array}$ & 0 & 0 \\
\hline
\end{tabular}

\section{Tepat Cara dan Lama Pemberian}

Tepat cara pemberian obat adalah ketepatan pemilihan bentuk sediaan obat yang diberikan sesuai dengan diagnosa kondisi pasien dan sifat obat. Misalnya per oral atau melalui mulut, per vaginal atau melalui vagina, parenteral melalui suntikan bisa intravena intramuskular 
subkutan atau topikal dioleskan di kulit seperti krim, gel, salep. Berdasarkan pengamatan yang telah dilakukan dan dengan melihat dari pedoman dalam Pedoman Pemakaian Antibiotik, maka pemberian keseluruhan telah mencapai $100 \%$ tepat lama pemberian.

Tabel 7 Tepat Cara, Lama Pemberian Dan Tepat Frekuensi

Pemberian Antibiotik pasien IGD

\begin{tabular}{lcc}
\hline Hal yang Diuji & Imlah & Persentasi \\
\hline Tepat cara & 744 & $100 \%$ \\
\hline Tepat lama pemberian & 744 & $100 \%$ \\
\hline Tepat frekuensi & 744 & $100 \%$ \\
\hline
\end{tabular}

\section{KESIMPULAN}

1. Golongan antibiotik yang sering digunakan pada pasien Instalasi Gawat Darurat Rumah Sakit Baptis Kediri periode April - Juni 2021 adalah golongan Cefalosporin sebanyak $67,1 \%$ dan Quinolon sebesar 25,9\% sedangkan untuk jenis antibiotik yang sering digunakan adalah Ceftriaxone $(31,0 \%)$ dan Levofloxacin $(24,1 \%)$.

2. Kesesuaian antibiotik dibandingkan dengan yang tertera dalam Pedoman Pengendalian Pemakaian Antibiotik di Instalasi Gawat Darurat Rumah Sakit Baptis Kediri periode April - Juni 2021 sudah sesuai $100 \%$.

\section{DAFTAR PUSTAKA}

AMRIN - Study Group. (2005). Penggunaan Antibiotik di RS Dr Soetomo Surabaya dan RSUP dr. Kariadi Semarang

Alon, T., Doepke, M., Rumsey, J.O., \& Tertilt, M. (2020). The Impact of COVID-19 on Gender Equality. NBER Working Paper 26947

Arif Zuhan, 2016, Profil Penanganan Luka pada Pasien Trauma di Instalasi Gawat Darurat Rumah Sakit Umum Provinsi Nusa Tenggara Barat, Jurnal Kedokteran Fakultas Kedokteran Universitas Mataram, Mataram Vol 5 No 3

Bismantara, Lintang., Ardya, Hanugrah., 2018 Gambaran Pola Peresepan Antibiotik Pada Resep Rawat Jalan Di Rumah Sakit X Kediri , Java Health Journal Universitas Kadiri, Vol 5 No 2

BKKBM Bandung, 2019, Rational Use Of Medicine (RUM), Burhan,Erlina., Susanto, Agus Dwi, Nasution.,Sally Aman dkk, (2020) Pedoman Tatalaksana COVID-19, Perhimpunan Dokter Paru Indonesia (PDPI)

Hanifah, Hananun Zharfa, 2016, Thesis : Evaluasi Penggunaan Antibiotik Empiris dan Analisis Biaya Demam Tifoid di Sebuah RS Swasta Kota Semarang. Fakultas Farmasi Universitas Gadjah Mada,

Ilmi, Tsamrotul., Yulia, Rika., Herawati,Fauna.,2020, Evaluasi Penggunaan Antibiotik Pada 
Pasien Pneumonia Di Rumah Sakit Umum Daerah Tulungagung, Jurnal Inovasi Farmasi Indonesia (JIFI) Vol. 1 No. 2

Kementerian Kesehatan RI, 2019. tentang Petunjuk Teknis Standar Pelayanan Kefarmasian di Rumah Sakit, Kementerian Kesehatan Republik Indonesia, Jakarta.

Manurung,Wanrajib Azhari, 2015, Tugas Akhir : Perancangan Rumah Sakit Umum Daerah (Rsud) Keas C Non Pendidikan Berbasis Low Cost, Universitas Islam Negeri (UIN) Maulana Malik Ibrahim, Malang

Peraturan Direktur Rumah Sakit Baptis Kediri tahun 2019, Panduan Pengendalian Penggunaan Antibiotik, Kediri

Peraturan Menteri Kesehatan Republik Indonesia Nomor 2406 Tahun 2011, Pedoman Umum Penggunaan Antibiotik Kementerian Kesehatan Republik Indonesia, Jakarta

Peraturan Menteri Kesehatan Republik Indonesia Nomor 72 Tahun 2016, Standar Pelayanan Kefarmasian di Rumah Sakit, Kementerian Kesehatan Republik Indonesia, Jakarta.

Rosalia, Priska, 2017, Skripsi : Pengaruh Pemberian Edukasi Pada Masyarakat Pengguna Antibiotik Di Sekitar Apotek " $X$ " Wilayah Surabaya Pusat, Fakultas Farmasi Universitas Katolik Widya Mandala, Surabaya
Santikrama, Wiweka , 2020, Skripsi: Evaluasi Penggunaan Antibiotik Secara Kuantitatif Dan Kualitatif Pada Pasien Penyakit Dalam Di Ruang Flamboyan Dan Virtual RSUD Dr. Iskak Tulungagung, UMM library, Malang

Setiabudy,Rianto, 2012, Farmakologi dan Terapi. Ed 5, Departemen Farmakologi dan Terapi Fakultas Kedokteran Universitas Indonesia I, Jakarta.

Setyawan, Budi, 2019, Manajemen Rumah Sakit, Zifatama, Sidoarjo 